\title{
Evaluating Student Performance and Perception of a Workshop Integrating Pharmacy Practice and a Pharmaceutics Lab
}

Daniel J. Hansen, PharmD ${ }^{1}$; Hemachand Tummala, PhD ${ }^{1}$; Wendy Jensen-Bender, PharmD ${ }^{1}$; Brittney A. Meyer, PharmD ${ }^{1}$; Surachat Ngorsuraches, $\mathrm{PhD}^{2 *}$

${ }^{1}$ South Dakota State University; ${ }^{2}$ Harrison School of Pharmacy Auburn University

*Dr. Ngorsuraches was a faculty member at South Dakota State University at the time of the project.

\begin{abstract}
Objective: Evaluating Student Performance and Perception of a Workshop Integrating Pharmacy Practice and a Pharmaceutics Lab Innovation: Common methods for curricular integration are often time and faculty-intensive. An innovative approach to integration was developed and utilized in an introductory compounding workshop. Faculty members collaborated with a compounding pharmacist to design and facilitate a pharmaceutics workshop for first-year pharmacy students. The workshop was composed of four major sections, an introduction to pharmaceutical compounding and the regulations surrounding manufacturing and sterility, a case discussion involving a pediatric patient and the need to develop an appropriate drug delivery system, a short review of pharmaceutical calculations and labeling requirements, and then an introduction to logistics and active learning in a lab setting.

Critical Analysis: After taking part in the workshop, students indicated a significantly higher comfort level going into the pharmaceutics lab (3.48 \pm 0.83 to $4.04 \pm 0.70)$ and in the compounding process $(3.06 \pm 0.83$ to $3.71 \pm 0.80)$. Their views of the clinical application of the lab and the need to use knowledge gained from other courses in the lab were also significantly improved (4.36 \pm 0.68 to $4.61 \pm 0.49$ and $3.71 \pm 0.77$ to $4.26 \pm 0.74$, respectively). In addition, their perceptions of how they will utilize the skills developed as a practicing pharmacist, and their feelings towards the safety procedures involved in compounding, were also positively affected (3.96 \pm 0.87 to $4.45 \pm 0.59$ and $3.28 \pm 0.92$ to 3.91 \pm 0.72 , respectively). Finally, students' average quiz score in Spring 2016, when the workshop was

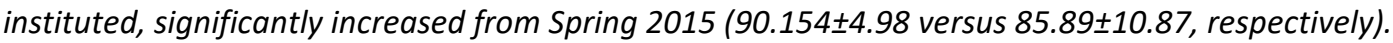

Key Words: curricular integration, pharmaceutics, pharmacy lab, compounding, pharmacy curriculum

\section{DESCRIPTION OF THE PROBLEM}

Many pharmacy programs are likely increasing curricular integration to meet the requirements within the new the Accreditation Council for Pharmacy Education (ACPE) Standards. Poirier, et al ${ }^{1}$ identified that curricular integration within pharmacy schools occurs commonly through integration of foundational sciences with therapeutics. The most common approaches for integration included organizing similar content from different disciplines in a course, incorporation in a skills lab or within pharmacy practice experiences. Multi-disciplinary case studies or examinations, team-based and problem-based learning, performance-based assessments (such as OSCEs), and senior assignments were additional methods acknowledged. Islam, et $\mathrm{al}^{2}$ identified lecture, case-based instruction/learning, and discussion/ recitation to be the most common pedagogical methods for

Corresponding Author: Daniel J. Hansen, PharmD

South Dakota State University

Box 2202C, Brookings, SD 57007

Phone: 605-688-6197; Email: Dan.Hansen@sdstate.edu integration, and included games, self-directed learning, journal clubs, simulations, workshops, and flipped classes as integration methods. Both studies identified faculty workload as a major challenge to implementing integration.

In Standard 10 of ACPE Standards 2016, colleges are asked to design and deliver a curriculum that emphasizes content integration throughout. ${ }^{3}$ It is not effective to only incorporate these aspects of integration towards the end of the curriculum, such as during advanced experiential learning. Instead, the foundational sciences and application of content should really be integrated within the curriculum from the start. Successful integration of patient care within the basic sciences has been published, and previous studies have specifically addressed integration for first-year pharmacy students. The Patient Care Project described by Brown, et $\mathrm{al}^{4}$ allowed students to use the knowledge they had gained in the basic science courses for patient care, Harold and McFalls ${ }^{5}$ outline an exercise for firstyear professional students in a pharmacy practice lab, and Karimi, et $\mathrm{al}^{6}$ described Learning Bridge assignments which were created by a team of faculty from basic, clinical, and social administrative sciences incorporating pharmaceutical sciences concepts learned during the first year of the professional program into introductory pharmacy practice experiences (IPPEs). Literature on integration for first-year 
students exists, but examples specific to pharmaceutics are limited.

Pharmaceutics plays a major role in the pharmacy profession and is a large part of what makes the profession unique. It applies physical and biological sciences to formulate products and effectively deliver them. Students need to be able to develop, integrate, and apply this knowledge to evaluate scientific literature, explain drug action, and solve clinical problems throughout their pharmacy careers, but unfortunately, students may miss the relevance of the basic science content to their future practice. It has been identified that students particularly struggle with applying pharmaceutical sciences concepts, such as those within pharmaceutics, to patient care. ${ }^{7}$ With this in mind, Stewart and others ${ }^{7}$ studied the integration of pharmaceutics and pharmacy practice courses within the Doctor of Pharmacy curriculum and found that a crossover assignment was an effective means for connecting specific pharmaceutics concepts and practice applications over the course of an entire semester. Stewart, et al. ${ }^{7}$ demonstrated that pharmaceutics is a potential course within a Doctor of Pharmacy curriculum that can be suitably integrated with pharmacy practice courses, but also highlighted the heavy workload sometimes involved in integration.

\section{STATEMENT OF INNOVATION}

To enhance curricular integration and potentially overcome the faculty workload struggles associated with integration throughout the entire semester, three clinical faculty members and one pharmaceutics faculty member developed a workshop centered on compounding, which emphasized the horizontal integration of knowledge from pharmaceutics and a pharmacy practice course. The goal was to find a place early in the curriculum, where faculty could show students how information in a basic science course is important to their future clinical practice, but design an approach much less time intensive than full course horizontal integration or other examples currently found in literature.

\section{THE EDUCATIONAL INNOVATION}

To design the integrated workshop, a team of three clinical faculty members and one pharmaceutics faculty member was formed as part of a larger college initiative to further integrate the curriculum. The group met, brainstormed, and discussed different opportunities, topics, and cases. The team ultimately decided the best way to integrate pharmaceutics and pharmacy practice courses would be to develop a team-taught workshop that emphasized the horizontal integration of the courses from two disciplines. Pharmacy practice was the clinical course chosen since it is the only practice-based content students receive in the first year.

At this institution, students are introduced to both pharmacy practice (part of a six-semester sequence of courses) and pharmaceutics (part of a two-semester sequence) in the fall semester of their first year. However, pharmaceutics only has a lab component in the spring semester. Therefore, it seemed logical to design a workshop for the beginning of the spring semester, just prior to the second course in each sequence and immediately before the lab component in pharmaceutics. While the clinical faculty had not previously taught in this course, the additional 3-hour workshop had minimal impact on their workload compared to a fully integrated course or lab series delivered throughout the semester.

A total of 82 first-year Doctor of Pharmacy students enrolled in the pharmaceutics course were required to attend the workshop. The workshop was composed of four major sections: an introduction to compounding pharmacy and the lab, a real-life case discussion, a review session on dispensing concepts, and then an introduction to active learning methodologies. The general concept of innovation was also introduced within the workshop, as many of the labs require students to overcome a real-life issue through innovation of a new dosage form. (Table 1).

After a brief introduction of the faculty, the team then introduced a specialty compounding pharmacist who spent time providing students with an overview of pharmaceutical compounding, handling hazardous materials and related regulations surrounding manufacturing and sterility. This practicing pharmacist volunteered her time for the presentation, which provided real-world application of pharmaceutics knowledge. Next, the students were divided into groups. One of the faculty members from the workshop development team, specializing in pediatrics, introduced a real-life case illustrating difficulty related to lack of flexibility in dose titration with medications available only as tablets in a neonatal patient and the need for an appropriate pediatric formulation. This portion of the workshop involved identifying problems associated with dispensing oral liquid fludrocortisone acetate formulations prepared from commercially available tablets to infants and designing a compounding strategy to solve the problem. The pharmacist presented data showing the suspension of crushed powder from fludrocortisone tablets in water or mothers breast milk failed to produce the desired therapeutic outcomes. The structure of the drug, along with its physicochemical properties, were provided. Student groups reviewed the case and discussed possible reasons for the failure of the formulation with the pharmaceutics faculty and the pharmacist including stability and absorption related issues. As students worked, the team of faculty answered student questions and prompted discussion. The class then came back together and the faculty elicited answers to the questions, providing further explanation as needed. The students determined, with the guidance of faculty, that based on the structure, the drug may be prone to oxidation by the excipients of the commercial tablet. Together, the class then participated 
in a problem-solving activity, led by the faculty member specializing in pharmaceutics, with a proposed formulation design that includes a water-soluble antioxidant ascorbic acid in the formulation.

In addition, there was an interactive review session led by the two remaining faculty members from the workshop development team following the case presentation, which included a brief review of pharmaceutical calculations for compounding, prescription reading, and labeling requirements. The workshop then ended with the pharmaceutics faculty member presenting on the pedagogical theory behind the new compounding laboratory teaching model that involves problem-solving and active learning strategies. He also presented on the topic of innovation and how to integrate the theoretical knowledge learned in pharmaceutics class into problem-solving in the compounding pharmacy. Finally, the workshop ended with a presentation on general overview of lab logistics. Some elements of the workshop such as prescription reading and calculations had been presented previously in the pharmacy practice course and were reinforced in the workshop in the context of compounding laboratory.

\section{CRITICAL ANALYSIS}

Since this workshop explored an instructional design to integrate pharmaceutics and pharmacy practice material, and it was the first time using this design, student perceptions of the pharmaceutics lab and academic performance were examined, using a pretest-posttest design. A self-administered survey (Table 2) including seven questions using a 5-point Likert scale was given just prior to the introduction (pre-test), and then a survey with the same seven questions and 5-point Likert scale, along with one open-ended question asking for students' overall thoughts, was administered at the completion of the workshop (post-test). To evaluate the impact on student performance, the average quiz score of students in Spring 2016 were compared to Spring 2015, when the curricular design of the lab course was fundamentally the same with the exception of the integrated workshop.

Although attendance was required for the pharmaceutics lab course, participation in the study was not. This workshop proposal was reviewed and approved by the University's Institutional Review Board. Academic performance and the survey data of student perceptions were descriptively analyzed (SPSS Statistics for Windows, Version 24.0). Average quiz scores and student perception scores, and standard deviations of each were calculated. Paired-samples and independent-samples t-tests at a significance level of 0.05 were used to test the differences.

\section{FINDINGS}

One student was unable to attend the workshop and all remaining students consented to participate in the study. As a result, the responses of 81 students (100\% response rate) were evaluated. Table 2 shows the student perceptions of the pharmaceutics lab. In general, comments received by students as part of the post-test were relatively positive, with the only negative aspect pointed out being the length of the workshop.

The average quiz score in Spring 2015 was $85.89 \pm 10.87$ (average score \pm S.D.) compared to $90.154 \pm 4.98$ in Spring 2016 $(p=0.002)$, when the workshop was instituted. The questions on the lab quiz related directly to the objectives covered in the workshop.

Upon completion of this workshop, academic performance improved and students responded favorably to the workshop as seen by the pre- and post-test survey results (Table 2 ). Not only did this integrated workshop make students feel more comfortable as they prepared to start pharmaceutics lab, but students were also able to see the clinical application of the lab, how they may use knowledge gained from other courses in the lab, and how they may use the skills gained in pharmaceutics as part of their role as a pharmacist. This shows the horizontal integration met its objective.

One of the benefits of coordinating the integration of content is that it gives faculty more time to revisit important concepts. It also allows those students repeated exposure, which is especially helpful for those who may have struggled in that area during its initial exposure, such as with pharmaceutical calculations. This supports the notion of integration beginning early and occurring often. Helping students make these connections early may help them to find their own connections within other courses as they progress through the curriculum.

Interestingly, while the students felt the workshop was informative and they were engaged in multiple forms of activelearning throughout the workshop, some students indicated via the survey that the workshop was a little long. Mental fatigue may have been a factor considering the workshop was delivered in the later afternoon, after students had attended all their other classes earlier in the day. It was also delivered in the classroom setting compared to the smaller cohort lab setting. First-year students are used to 50-minute lecture blocks, with labs in the first semester lasting 2-hours. Since this was the first time students were exposed to a 3-hour period of instruction, which is the same amount of time as their pharmaceutics lab going forward, students were likely not prepared for this block of time.

Stewart, et al. ${ }^{7}$ also had positive results when trying to integrate a pharmaceutics and a pharmacy practice course, but the designed integration was much different. Three faculty 
members met to develop a crossover assignment. The assignment required faculty to coordinate course schedules to bridge the two courses and align course content. Faculty members also spent time teaching and coaching each other on their content to provide a unified approach to questions over the assignment. During delivery, the faculty were present for both launch of the assignment and follow-up discussion one month later. Overall, the time commitment for faculty involved was much more intense, occurring both before and throughout the semester. The design of this workshop allowed the faculty members involved to use the equivalent of one pharmaceutics lab period and required much less coordination.

\section{NEXT STEPS}

As schools increase curricular integration, and since the amount and method of integration varies widely, it is important to find innovative ways to integrate curricular content. This integrated workshop positively impacted academic performance, student comfort going into the pharmaceutics lab and with the compounding process, and aided recognition of the clinical application of the pharmaceutics lab and the need to use knowledge gained from other courses in the lab. The description within this article can be used as a model to provide horizontal integration between pharmacy practice and pharmaceutics. This delivery format, which overcomes several challenges of other methods, could also be tailored for other courses in the pharmacy curriculum.

Acknowledgements: None

Funding/Support: None

Conflicts of Interest: None

\section{References}

1. Poirier TI, Fan J, and Nieto MJ. Survey of pharmacy schools' approaches and attitudes toward curricular integration. Am J Pharm Educ. 2016;80(6):Article 96. doi: $10.5688 /$ ajpe80696

2. Islam MA, Talukder RM, Taheri R, and Blanchard N. Integration of basic and clinical science courses in US PharmD programs. Am J Pharm Educ. 2016;80(10):Article 166. doi: 10.5688/ajpe8010166

3. Accreditation Council for Pharmacy Education. Accreditation standards and key elements for the professional program in pharmacy leading to the doctor of pharmacy degree ("Standards 2016"). Chicago, III; 2015. https://www.acpeaccredit.org/pdf/Standards2016FINAL.pdf. Accessed August 10, 2018.

4. Brown B, Skau K, and Wall A. Learning across the curriculum: Connecting the pharmaceutical sciences to practice in the first professional year. Am J Pharm Educ. 2009;73(2):Article 36. doi: 10.5688/aj730236

5. Harrold MW and McFalls MA. A pharmacy practice laboratory exercise to apply biochemistry concepts. Am J Pharm Educ. 2010;74(8):Article 144. doi: 10.5688/aj7408144

6. Karimi R, Arendt CS, Cawley P, Buhler AV, Elbarbry F, Roberts SC. Learning Bridge: Curricular integration of didactic and experiential education. Am J Pharm Educ. 2010;74(3):Article 48. doi: 10.5688/aj740348

7. Stewart AL, Buckner IS, Wildfong PL. A shared assignment to integrate pharmaceutics and pharmacy practice course concepts. Am J Pharm Educ. 2011;75(3):Article 44. doi: 10.5688/ajpe75344a 
Table 1. Workshop sections, goals and time allocation

\begin{tabular}{|c|c|c|c|}
\hline Workshop Sections & Instructors' Objectives & Time Allotted & $\begin{array}{l}\text { Faculty } \\
\text { Member }\end{array}$ \\
\hline Pre-Survey & - $\quad$ Captured students' perceptions of the pharmaceutics laboratory & 5 minutes & \\
\hline $\begin{array}{l}\text { Introduction to } \\
\text { compounding } \\
\text { pharmacy }\end{array}$ & $\begin{array}{l}\text { - Introduce students to the field of compounding } \\
\text { - } \quad \text { Outline regulations surrounding manufacturing and sterility }\end{array}$ & 45 minutes & $\begin{array}{l}\text { Compounding } \\
\text { Pharmacist }\end{array}$ \\
\hline & Break & 15 minutes & \\
\hline $\begin{array}{l}\text { Introduction to } \\
\text { Pharmaceutics Lab }\end{array}$ & $\begin{array}{l}\text { - Discuss active learning and the integration of theoretical } \\
\text { knowledge in compounding } \\
\text { - Define laboratory logistics }\end{array}$ & 45 minutes & $\begin{array}{l}\text { Pharmaceutics } \\
\text { lab instructor } \\
\text { (Tummala) }\end{array}$ \\
\hline Post-Survey & Same as the pre-survey with an additional open-ended question & 5 minutes & \\
\hline
\end{tabular}


Table 2 - Student perceptions of the pharmaceutics lab $(\mathrm{N}=81)$

Survey Question

1. How comfortable do you feel going into Pharmaceutics Lab? ${ }^{\wedge}$

2. How comfortable do you feel about the compounding process? ${ }^{\wedge}$

3. Can you see the clinical application of the Pharmaceutics Lab? ${ }^{\dagger}$

4. How often do you think you will use knowledge gained from other courses in Pharmaceutics Lab? ¥

5. I see myself using the skills gained in Pharmaceutics Lab as part of my role as a pharmacist. ${ }^{* *}$

6. How comfortable do you feel about the safety procedures involved in compounding? ${ }^{\wedge}$

7. I would like to see active learning as part of Pharmaceutics Lab. ${ }^{* *}$
Pre-workshop score

(Average \pm S.D.)
Post-workshop score

(Average \pm S.D.)
$3.48 \pm 0.83$

$3.06 \pm 1.00$

$4.36 \pm 0.68$

$3.71 \pm 0.77$

$3.96 \pm 0.87$

$3.28 \pm 0.92$

$4.20 \pm 0.79$
$4.04 \pm 0.70 *$

$3.71 \pm 0.80$ *

$4.61 \pm 0.49 *$

$4.26 \pm 0.74 *$

$4.45 \pm 0.59 *$

$3.91 \pm 0.72 *$

$4.43 \pm 0.76$

*P-Value $<0.05$ when comparing the difference between pre- and post-test

$\wedge 1$ - not at all comfortable; 2 - somewhat uncomfortable; 3 - neutral; 4 -somewhat comfortable; 5 -totally comfortable †1 - not at all; 2 -somewhat unclear; 3 -neutral; 4 -somewhat clear; 5 -totally clear $\$ 1-$ not at all; $2-<25 \%$ of the time; $3-25-50 \%$ of the time $4-50-75 \%$ of the time; $5->75 \%$ of the time

**1 - unsure; 2 - not at all; 3 - possibly; 4 - very likely; 5 - absolutely 